\title{
Competitiveness of Rhizobium leguminosarum bv. trifolii Strains in Mixed Inoculation of Clover (Trifolium pratense)
}

\author{
JERZY WIELBO*, MONIKA MAREK-KOZACZUK, DOMINIKA KIDAJ \\ and ANNA SKORUPSKA \\ Department of Genetics and Microbiology, Maria Curie-Skłodowska University \\ Lublin, Poland
}

Received 10 April 2010, revised 10 January 2011, accepted 14 January 2011

\begin{abstract}
Rhizobium leguminosarum bv. trifolii (Rlt) establishes beneficial root nodule symbiosis with clover. Twenty Rlt strains differentially marked with antibiotic-resistance markers were investigated in terms of their competitiveness and plant growth promotion in mixed inoculation of clover in laboratory experiments. The results showed that the studied strains essentially differed in competition ability. These differences seem not to be dependent on bacterial multiplication in the vicinity of roots, but rather on complex physiological traits that affect competitiveness. The most remarkable result of this study is that almost half of the total number of the sampled nodules was colonized by more than one strain. The data suggest that multi-strain model of nodule colonization is common in Rhizobium-legume symbiosis and reflects the diversity of rhizobial population living in the rhizosphere
\end{abstract}

K e y w ord s: clover growth promotion, competitiveness, mixed inoculation, rhizobia

\section{Introduction}

Biological nitrogen fixation (BNF) is a process in which atmospheric dinitrogen is reduced to forms available to plants and is provided by free-living bacteria or bacteria symbiotically associated with leguminous plants, commonly known as rhizobia. Rhizobia belong to different taxonomic families of $\alpha$-proteobacteria such as Rhizobiaceae, Phylobacteriaceae and Bradyrhizobiaceae, and to $\beta$-proteobacteria such as the recently described Burkholderia spp. (reviewed by Perret et al., 2000; Masson-Boivin et al., 2009). Significance of rhizobial symbioses in agriculture stems from providing an extra source of nitrogen for plant growth, supplementing low nitrogen level in the soil and replacing nitrogenous fertilizer (Peoples et al., 1995; Ramos et al., 2001).

Rhizobium leguminosarum bv. trifolii $(R l t)$ induces and colonizes nodules elicited on roots of clover (Trifolium spp.). The symbiosis between rhizobia and legumes is a multi-step process including the exchange of molecular signals between the microsymbiont and its host (reviewed by, Perret et al., 2000; Spaink, 2000; Jones et al., 2007). Initially, flavonoids released by plants attract bacteria to the roots and induce synthesis of bacterial Nod factors that are lipochitooligosaccharide signals that trigger several plant responses, such as root hair curling and differentiation of plant meristems leading to the formation of root nodules. Nodules are colonized by rhizobia via tubular structures known as infection threads in which rhizobia multiply. After releasing from infection threads bacteria surrounded by peribacteroid membranes colonize nodule tissue forming symbiosomes in which bacteria are converted into bacteroids. Bacteroids localized in the symbiotic zone of mature nodules reduce atmospheric dinitrogen into forms, which are easily assimilated by plants (Vasse et al., 1990; Timmers et al., 2000).

Competition for nodulation is a quantitative phenotype, which determines the ability of Rhizobium strains to dominate in the nodules of a given legume host in competition with other strains present in the root rhizosphere (Dowling and Broughton, 1986). Soil populations of Rhizobium usually consist of numerous strains,

* Corresponding author: J. Wielbo, Department of Genetics and Microbiology, Maria Curie-Skłodowska University, Akademicka 19 st., 20-033 Lublin, Poland; e-mail: jerzy.wielbo@poczta.umcs.lublin.pl 
which compete with each other during the phase of vegetative growth in the soil, as well as during several stages of plant colonization and nodule formation (Wilson et al., 1998; Stuurman et al., 2000; Duodu et al., 2009). Rhizobial strains are genetically and metabolically diverse, reveal significant differentiation in competitive fitness to infect and occupy nodule of the host plant and differ in the symbiotic activities (Maier and Triplett, 1996; Wielbo et al., 2007; Depret and Laguerre, 2008). To investigate the competition between rhizobial strains, numerous molecular markers were developed and employed. Spontaneous or acquired antibiotic resistance markers are commonly used due to feasibility of detection and a broad differentiation allowing simultaneous identification a number of strains (Sharma et al., 1991; Cresswell et al., 1994; Sessitsch et al., 1998; Wilson et al., 1998; Stuurman et al., 2000).

In this work, we investigated the competition ability of $20 \mathrm{Rlt}$ strains originating from clover root nodules under laboratory conditions. The results showed that in most cases simultaneous inoculation of plants with a mixture of rhizobial strains carrying different antibiotic resistance markers resulted in nodule colonization by more than one strain. The commonly observed nodule colonization by multiple strains that differ in respect to the efficiency of plant growth promotion may have significant impact on overall symbiosis in the soil.

\section{Experimental}

\section{Materials and Methods}

Rhizobium leguminosarum bv. trifolii strains. 20 Rlt strains used in this study were obtained from nodules of clover (Trifolium pratense) cultivated in arable sandy loam soil in the region of Lublin, Poland. Rifampicin, streptomycin and trimethoprim-resistant spontaneous mutants were obtained as follow: from overnight cultures of Rlt isolates grown in liquid TY medium (Sambrook et al., 1989) with constant shaking, about $5 \times 10^{9} \mathrm{cfu} / \mathrm{ml}$ of the given culture was plated on TY agar medium supplemented with rifampicin, streptomycin or trimethoprim $(40 \mu \mathrm{g} / \mathrm{ml}$, $200 \mu \mathrm{g} / \mathrm{ml}, 200 \mu \mathrm{g} / \mathrm{ml}$, respectively). Single colonies resistant to appropriate antibiotic were isolated. Nalidixic acid for selection of naturally resistant strains was used in the concentration of $150 \mu \mathrm{g} / \mathrm{ml}$. Tetracycline resistant $R l t$ strains were obtained by introducing pJBA21 Tc plasmid via triparental conjugation (Wielbo and Skorupska, 2001). Each of 20 strains was resistant to one of the following antibiotics: rifampicin, streptomycin, tetracycline, trimethoprim and nalidixic acid (Table I).
Table I

Relevant characteristics of Rhizobium leguminosarum bv. trifolii strains used in this study

\begin{tabular}{|l|l|l|l|l|}
\hline Group I & \multicolumn{1}{|c|}{ Group II } & Group III & Group IV & Group V \\
\hline $\mathrm{K} 416 \mathrm{Tm}^{\mathrm{R}}$ & $\mathrm{K} 417 \mathrm{Rf}^{\mathrm{R}}$ & $\mathrm{K} 38 \mathrm{Rf}^{\mathrm{R}}$ & $\mathrm{K} 29 \mathrm{Tc}^{\mathrm{R}}$ & $\mathrm{K} 313 \mathrm{Tc}^{\mathrm{R}}$ \\
\hline $\mathrm{K} 411 \mathrm{Rf}^{\mathrm{R}}$ & $\mathrm{K} 108 \mathrm{Tm}^{\mathrm{R}}$ & $\mathrm{K} 413 \mathrm{Nal}^{\mathrm{R}}$ & $\mathrm{K} 87 \mathrm{Str}^{\mathrm{R}}$ & $\mathrm{K} 312 \mathrm{Str}^{\mathrm{R}}$ \\
\hline $\mathrm{K} 36 \mathrm{Str}^{\mathrm{R}}$ & $\mathrm{KO} 17 \mathrm{Tc}^{\mathrm{R}}$ & $\mathrm{KO} 18 \mathrm{Tc}^{\mathrm{R}}$ & $\mathrm{K} 322 \mathrm{Nal}^{\mathrm{R}}$ & $\mathrm{K} 415 \mathrm{Rf}^{\mathrm{R}}$ \\
\hline $\mathrm{KO} 27 \mathrm{Tc}^{\mathrm{R}}$ & $\mathrm{K} 71 \mathrm{Str}^{\mathrm{R}}$ & $\mathrm{K} 91 \mathrm{Str}^{\mathrm{R}}$ & $\mathrm{K} 810 \mathrm{Rf}^{\mathrm{R}}$ & $\mathrm{K} 107 \mathrm{Tm}^{\mathrm{R}}$ \\
\hline
\end{tabular}

The spontaneous mutants were isolated in the case of $\mathrm{Rf}^{\mathrm{R}}-$ rifampicin resistance, $\mathrm{Str}^{\mathrm{R}}$ - streptomycin resistance and $\mathrm{Tm}^{\mathrm{R}}$ - trimethoprim resistance. $\mathrm{Tc}^{\mathrm{R}}$ - tetracycline resistant strains were obtained by introducing pJBA21Tc plasmid. $\mathrm{Nal}^{\mathrm{R}}$ - natural nalidixic acid resistance.

Plant tests. Red clover seeds (Trifolium pratense L. cv. Dajana) were surface-sterilized, germinated on TY agar medium, and then transferred onto agar slants with nitrogen-free Fåhraeus medium (Vincent, 1970). Clover seedlings were inoculated with $200 \mu 1$ single strain suspension in water, which was scratched from TY agar medium plate, or with $200 \mu 1$ mixture of four strains differently tagged with antibiotic-resistance marker $(1: 1: 1: 1 \mathrm{v} / \mathrm{v})$. In both cases the bacterial suspensions contained about $1.0 \times 10^{9} \mathrm{cfu} / \mathrm{ml}$. Plants were grown in a greenhouse under natural light supplemented with artificial light $(14 \mathrm{~h}$ day/10 h night, at $24 / 19^{\circ} \mathrm{C}$ ). After 5 weeks, clover plants were harvested and nodules were counted. The efficiency of symbiotic nitrogen fixation was estimated by weighing fresh mass of shoots and roots. For each experimental group 20 plants were used and two independent experiments were conducted.

Estimation of rhizobial competitiveness. Ten clover plants were randomly chosen from each experimental group inoculated with a mixture of four strains and wet masses of shoots and roots were estimated. Root nodules were surface-sterilized and the content of individual nodules was plated on TY agar medium. Colonies derived from individual nodules were used for preparation of water suspension an $\mathrm{OD}_{550}$ of 0.05 $\left(\sim 5 \times 10^{7} \mathrm{cfu} / \mathrm{ml}\right) .20 \mu \mathrm{l}$ of each suspension was spotted on a set of TY agar medium plates containing one of four antibiotics, depending on antibiotic resistance markers carried by strains in a particular mixture. Bacteria were grown for three days at $28^{\circ} \mathrm{C}$. Detectable growth on only one plate from a set was interpreted as the presence of pure culture in the nodule, whereas the growth on more than one plate from a set was interpreted as mixed colonization of nodule.

Rhizobial growth assay. $5 \mathrm{ml}$ Fåhraeus medium supplemented with appropriate amount of TY medium was inoculated with $50 \mu 1$ of overnight culture of Rlt strains growing in TY medium, and incubated for 2 days at $28^{\circ} \mathrm{C}$. Bacterial growth was measured by monitoring $\mathrm{OD}_{550}$. For all tested strains the experiment was conducted in triplicate. 

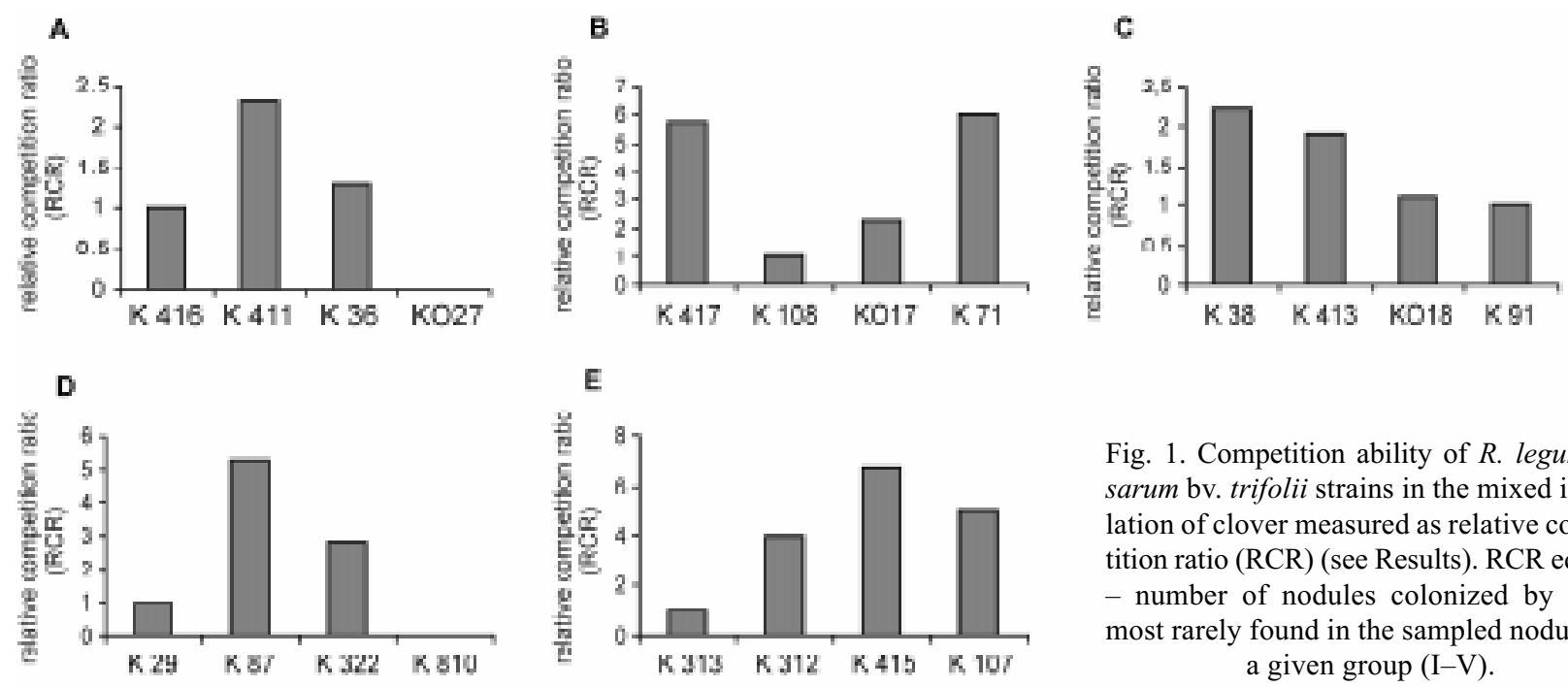

Fig. 1. Competition ability of $R$. leguminosarum bv. trifolii strains in the mixed inoculation of clover measured as relative competition ratio (RCR) (see Results). RCR equal 1 - number of nodules colonized by strain most rarely found in the sampled nodules of a given group (I-V).

\section{Results}

To study nodulation competitiveness, twenty $R l t$ strains were divided into five groups (I-V). Strains were assigned to groups randomly, and four strains belonging to the same group differed from each other with respect to the antibiotic resistance markers they were carrying (Table I). Clover seedlings were inoculated with individual strains or with a mixture of four strains belonging to a given group. After 5 weeks, samples of nodules were taken and rhizobia were recovered from nodules by selection on TY medium supplemented with an appropriate antibiotic. In the case of groups II, III and V, all four strains used for clover inoculation were recovered from the nodules, whereas in the case of groups I and IV, three of four strains used for inoculation were found in the sampled nodules. For Rlt strains assigned to a given group the "relative competition ratio" (RCR) was calculated as follow: (a) the number of nodules occupied by the least frequently found strain was normalized to 1 ; (b) RCR for the three other strains were calculated by dividing the number of nodules colonized by a particular strain by the number of nodules occupied by the least frequent strain; (c) if a strain was absent in all tested nodules, the RCR was 0 (Fig. 1A, B, C, D, E). As regards their high "relative competition value", K411 (group I), K417, K71 (group II), K38, K413 (group III), K87 (group IV) and K415 (group V) strains can be considered competitive. On the other hand, $\mathrm{KO} 27$ and $\mathrm{K} 810$ strains were not recovered from the sampled nodules and they were considered uncompetitive.

Based on the antibiotic resistance selection of Rlt strains recovered from clover nodules, it has been found that nodules occupied by only one strain comprised at average $56 \pm 7 \%$ (Fig. $2 \mathrm{~A}, \mathrm{~B}, \mathrm{C}, \mathrm{D}, \mathrm{E}$ ). The others nodules were occupied by two or three strains that were distinguished by different antibiotic markers. Two-strain nodule occupancy ranged from $28 \%$ to
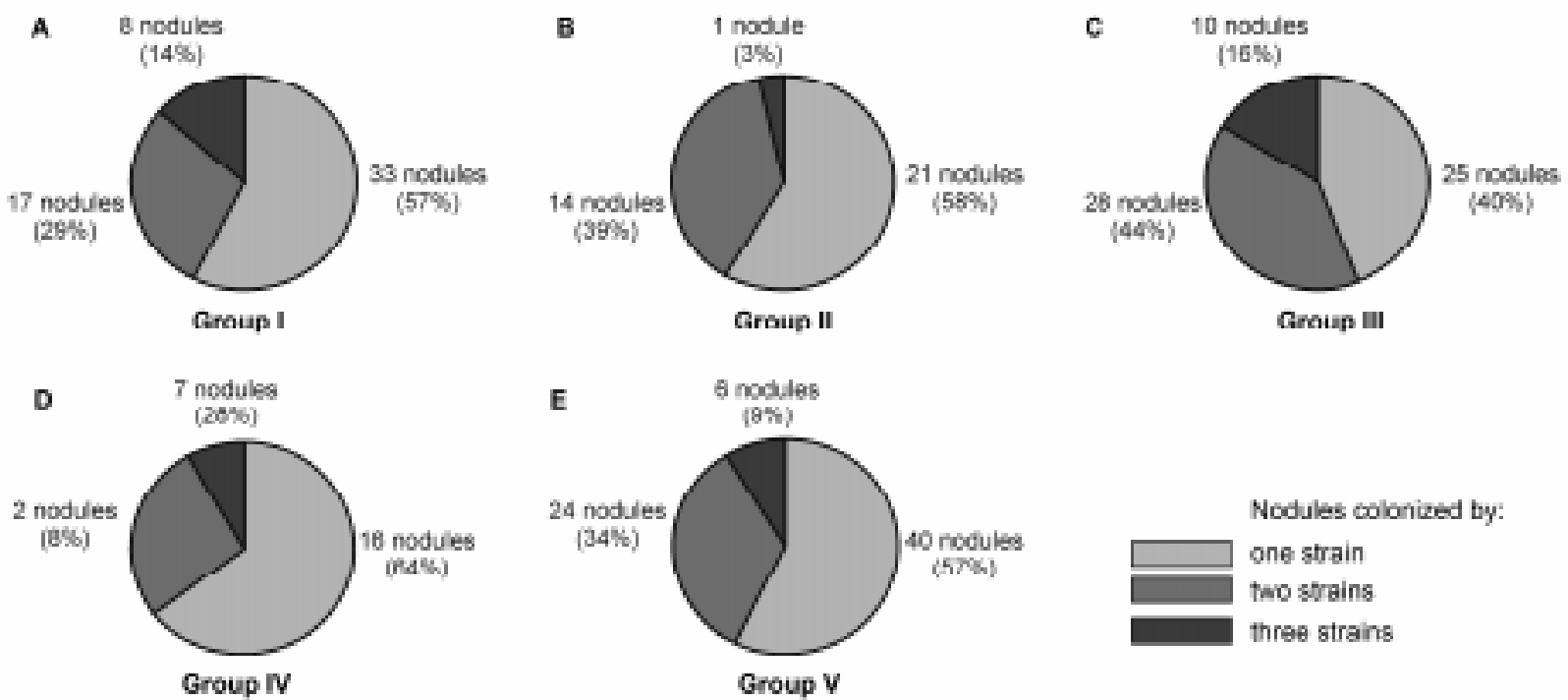

Nodules colanizod by:

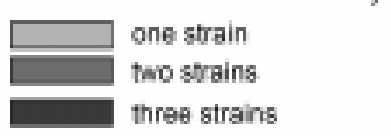

Fig. 2. Distribution of nodules infected by one, two or three strains in particular groups of R. leguminosarum bv. trifolii strains. 
Table II

Symbiotic activity of $R$. leguminosarum bv. trifolii strains

\begin{tabular}{|c|c|c|c|c|}
\hline Rlt strain number & No of nodules/plant & $\begin{array}{c}\text { Fresh mass } \\
\text { of shoots/plant }(\mathrm{mg})\end{array}$ & $\begin{array}{c}\text { Fresh mass } \\
\text { of roots/plant }(\mathrm{mg})\end{array}$ & $\begin{array}{c}\text { Fresh mass } \\
\text { of plant/nodule }(\mathrm{mg})\end{array}$ \\
\hline \multicolumn{5}{|c|}{ Group I of Rlt strains } \\
\hline K 416 & $5.4 \pm 1.5 \mathrm{a}$ & $26.3 \pm 3.5 \mathrm{a}$ & $22.7 \pm 1.3 \mathrm{a}$ & 9.0 \\
\hline K 411 & $6.8 \pm 0.7 \mathrm{a}$ & $31.3 \pm 9.4 \mathrm{a}$ & $29.7 \pm 10.2 \mathrm{a}$ & 8.9 \\
\hline K 36 & $4.3 \pm 1.0 \mathrm{a}$ & $36.8 \pm 2.1 \mathrm{a}$ & $18.5 \pm 3.6 \mathrm{a}$ & 12.8 \\
\hline $\mathrm{KO} 27$ & $6.6 \pm 2.3 \mathrm{a}$ & $28.6 \pm 6.6 \mathrm{a}$ & $32.3 \pm 5.3 \mathrm{a}$ & 9.2 \\
\hline Mixed inoculation (I) & $7.4 \pm 2.2 \mathrm{a}$ & $36.2 \pm 8.3 \mathrm{a}$ & $23.7 \pm 7.4 \mathrm{a}$ & 8.1 \\
\hline \multicolumn{5}{|c|}{ Group II of Rlt strains } \\
\hline K 417 & $7.0 \pm 0.7 \mathrm{~b}$ & $45.8 \pm 9.3 \mathrm{ab}$ & $25.6 \pm 11.6 \mathrm{a}$ & 10.2 \\
\hline K 108 & $5.4 \pm 0.7 \mathrm{ab}$ & $50.9 \pm 8.5 \mathrm{~b}$ & $26.5 \pm 10.0 \mathrm{a}$ & 14.3 \\
\hline KO17 & $3.6 \pm 0.4 \mathrm{a}$ & $33.4 \pm 1.9 \mathrm{a}$ & $12.6 \pm 4.2 \mathrm{a}$ & 12.7 \\
\hline K 71 & $3.7 \pm 0.6 \mathrm{a}$ & $34.2 \pm 8.6 \mathrm{a}$ & $13.7 \pm 3.8 \mathrm{a}$ & 13.0 \\
\hline Mixed inoculation (II) & $4.7 \pm 1.9 \mathrm{ab}$ & $30.5 \pm 10.0 \mathrm{a}$ & $10.5 \pm 6.3 \mathrm{a}$ & 8.8 \\
\hline \multicolumn{5}{|c|}{ Group III of Rlt strains } \\
\hline K 38 & $5.2 \pm 2.0 \mathrm{a}$ & $36.6 \pm 4.1 \mathrm{a}$ & $16.0 \pm 0.9 \mathrm{a}$ & 10.1 \\
\hline K 413 & $8.6 \pm 2.1 \mathrm{a}$ & $44.3 \pm 2.5 \mathrm{a}$ & $39.4 \pm 7.0 \mathrm{~b}$ & 9.8 \\
\hline KO18 & $10.2 \pm 0.9 \mathrm{a}$ & $68.5 \pm 7.3 \mathrm{~b}$ & $43.3 \pm 7.1 \mathrm{~b}$ & 11.0 \\
\hline K 91 & $5.8 \pm 2.7 \mathrm{a}$ & $56.6 \pm 3.0 \mathrm{c}$ & $40.0 \pm 12.5 \mathrm{~b}$ & 16.6 \\
\hline Mixed inoculation (III) & $9.0 \pm 2.8 \mathrm{a}$ & $33.9 \pm 3.4 \mathrm{a}$ & $24.9 \pm 6.3 \mathrm{ab}$ & 6.5 \\
\hline \multicolumn{5}{|c|}{ Group IV of Rlt strains } \\
\hline K 29 & $3.6 \pm 1.2 \mathrm{a}$ & $31.2 \pm 7.0 \mathrm{a}$ & $12.1 \pm 2.0 \mathrm{a}$ & 12.2 \\
\hline K 87 & $2.8 \pm 0.7 \mathrm{a}$ & $24.6 \pm 9.4 \mathrm{a}$ & $12.4 \pm 4.1 \mathrm{a}$ & 13.4 \\
\hline K 322 & $4.2 \pm 1.8 \mathrm{a}$ & $34.6 \pm 9.2 \mathrm{a}$ & $18.8 \pm 8.2 \mathrm{ab}$ & 12.7 \\
\hline K 810 & $6.8 \pm 1.6 \mathrm{~b}$ & $29.5 \pm 4.5 \mathrm{a}$ & $21.8 \pm 5.5 \mathrm{~b}$ & 7.5 \\
\hline Mixed inoculation (IV) & $3.3 \pm 0.9 \mathrm{a}$ & $25.2 \pm 7.1 \mathrm{a}$ & $10.4 \pm 2.5 \mathrm{a}$ & 10.9 \\
\hline \multicolumn{5}{|c|}{ Group V of $R l t$ strains } \\
\hline K 313 & $3.8 \pm 1.5 \mathrm{a}$ & $44.1 \pm 12.9 \mathrm{a}$ & $23.7 \pm 10.5 \mathrm{ab}$ & 17.7 \\
\hline K 312 & $3.4 \pm 1.0 \mathrm{a}$ & $35.0 \pm 7.0 \mathrm{a}$ & $13.3 \pm 2.1 \mathrm{a}$ & 14.4 \\
\hline K 415 & $6.2 \pm 1.2 \mathrm{ab}$ & $41.3 \pm 0.9 \mathrm{a}$ & $22.8 \pm 5.0 \mathrm{~b}$ & 10.4 \\
\hline K 107 & $5.1 \pm 1.6 \mathrm{ab}$ & $55.3 \pm 10.4 \mathrm{a}$ & $27.4 \pm 8.1 \mathrm{~b}$ & 16.4 \\
\hline Mixed inoculation $(\mathrm{V})$ & $6.8 \pm 0.4 \mathrm{~b}$ & $44.7 \pm 7.0 \mathrm{a}$ & $25.7 \pm 6.1 \mathrm{~b}$ & 10.3 \\
\hline \multicolumn{5}{|c|}{ Average values } \\
\hline Inoculation by individual strains & $6.2 \pm 2.3 \mathrm{a}$ & $34.1 \pm 7.2 \mathrm{a}$ & $19.0 \pm 7.9 \mathrm{a}$ & $12.1 \pm 2.8 \mathrm{a}$ \\
\hline Inoculation by a mixture of strains & $5.4 \pm 1.9 \mathrm{a}$ & $39.4 \pm 11.4 \mathrm{a}$ & $23 \pm 9.6 \mathrm{a}$ & $8.9 \pm 1.8 \mathrm{~b}$ \\
\hline
\end{tabular}

Values are the mean \pm standard deviation of 20 clover plants in experiment. Means within the same column and followed by the same letter are not significantly different $(P>0.05)$.

$40 \%$, and three-strain nodule occupancy from $3 \%$ to $16 \%$ of nodules, depending on the group of strains (I-V) used for clover inoculation (Fig. 2 A, B, C, D, E). Nodules simultaneously colonized by all four strains were not detected. The obtained results showed that nodule colonization by more than one strain was prevalent, at least in competition experiments conducted under laboratory conditions.

Rlt strains used in competition experiments were characterized with regard to the symbiotic properties such as nodulation ability and plant growth promotion (Table II). The tested strains varied both in the number of nodules elicited and in the impact on fresh mass of clovers. In the case of some strains the differences in nodule number and shoot and root mass were statistically significant. It is worth noting that plants inoculated with a mixture of four strains showed intermediary values of symbiotic parameters, which can reflect averaged effects of individual strains on symbiosis. In almost all cases, fresh mass of total plant per nodule was lower in the mixed inoculation in comparison to the same parameter in clover inoculation by individual strains (Table II).

The differences observed in the nodule colonization ability of Rlt strains might result from some physiological differences between the strains, for instance, in the growth rate. In the competition experiment, the mixtures of strains used as inocula were prepared by mixing equal volumes of four bacterial water suspensions with the same $\mathrm{OD}_{550}$, which should minimize the effect of possible differences in the initial cell density. In addition, growth of rhizobia was 
assayed in the medium composed of nitrogen-free Fåhraeus medium used in plant tests supplemented with $1 \%, 2 \%, 5 \%, 10 \%$ or $20 \%$ TY medium. It was assumed that addition of some amount of TY to the plant medium allows for the growth of bacteria while simultaneously resembling the plant growth medium. Rhizobia were grown in these media for 2 days and $\mathrm{OD}_{550}$ was measured. The results showed that Rlt strains used in the competition experiments grow weakly and only in Fåhraeus medium supplemented with $10 \%$ or $20 \%$ of TY, reaching $\mathrm{OD}_{550}$ values from 0.13 to 0.2 (data not shown). Differences in growth of strains on Fåhraeus medium supplemented with $10 \%$ TY, as well as on medium supplemented with $20 \%$ TY were observed, however, the analysis of variance indicated that these differences were statistically insignificant (data not shown). In conclusion, the possible differences in the initial growth of Rlt strains on plant medium at the time of inoculation could not essentially affect their competitiveness.

\section{Discussion}

Local population of $R$. leguminosarum specific for a given legume host is composed of numerous strains characterized by great variability in genetic and metabolic traits (Lakzian et al., 2002; Wielbo et al., 2010). Rhizobial competitiveness is a complex process dependent on genetic and overall metabolic status of bacteria (Wielbo et al., 2007), susceptibility to plant molecular signals (Mabood et al., 2008; Maj et al., 2010), motility of bacteria (Mellor et al., 1987), production of/ resistance to bacteriocins (Wilson et al., 1998) or even distribution of bacteria in the soil (Lopez-Garcia et al., 2002). Several studies indicate that both the legume hosts and microsymbionts affect the outcome of rhizobial competition (Kiers et al., 2006; Depret and Laguerre, 2008; Rangin et al., 2008).

All these and other variables characterizing individual strains influence their overall competition abilities. As a result, appreciable variability in rhizobial competitiveness is observed, both in highly controlled experiments under laboratory conditions, and in experiments carried out in the soil (Maier and Triplett, 1996; Svenning et al., 2001; Wielbo et al., 2007; Duodu et al., 2009; Sachs et al., 2009).

The strains compete with each other on the level of root adsorption, root hair infection, growth inside the infection threads, nodule tissue colonization and survival after release into the soil, where they constitute part of population capable of symbiotic interactions (Duodu et al., 2005; Silva et al., 2007; Rangin et al., 2008; Sachs et al., 2009). Less competitive rhizobia comprising another part of the population may be eliminated from nodule infection (Streeter,
1994). Finally, nonsymbiotic rhizobia constitute the fraction that lost the nodulation genes but is still able to colonize root surfaces and can play an important role in competition (Sachs et al., 2009).

In several studies, the competition between rhizobia was commonly investigated in a two-strain competition assay under controlled conditions. In this assay both strains were tagged with different markers such as antibiotic resistance genes (Bromfield, 1984), lux (Cresswell et al., 1994) or $g f p$ reporter genes (Stuurman et al., 2000) and occupancy of both strains was easily determined in the nodule. The drawback of this method is the extreme simplification of the model, which does not reflect native conditions. The second most frequently used method for rhizobial competition analysis was to use a single marked strain vs. the entire unmarked soil population composed of numerous strains. Major drawback of this approach is lack of any information about the unmarked strains possibly present in the nodules. Recently, the competitiveness of unmarked rhizobial strains was studied by molecular identification of particular genotypes occupying the nodules (Svenning et al., 2001).

In the present work, the two methods have been combined, and clover plants were inoculated by four differently marked strains. It allowed determining the differences in competitive ability of the individual strains, and the predominance of nodules occupied by more than one strain, in the case of a mixed inoculation. It is worth noting that infection by several strains negatively affected plant growth promotion when compared to single-strain infection.

Past studies showed mixed colonization of infection threads and nodules (Bromfield, 1984) in a twostrain competition assay (Stuurman et al., 2000; Gage, 2004). Expanding the competition test to clover inoculation by four strains, we demonstrated the possibility of single clover nodule colonization by three different strains. The percent of nodules colonized by three strains was relatively low and ranged from 3 to $16 \%$ of the sampled nodules. Nodules colonized by four strains were not found. It is possible that the number of the sampled nodules should have been greater to allow detection of nodules occupied by all four strains. On the other hand, the limited space available in the infection threads and/or in young nodules might restrict the growth of rhizobia, and this might also explain why four strain nodule colonization was not observed. The most important finding from the presented study is that almost half of the total number of the sampled nodules was colonized by more than one strain. It suggests that multistrain model of nodule colonization is predominant also in the soil environment, and reflects the complexity and diversity of rhizobial population in the rhizosphere. 
The comparison of symbiotic efficiencies of clover inoculation by individual strains $v s$. a mixture of strains was not conclusive. Whereas, significant differences between the averaged data of shoots and roots masses in single strain inoculation and in the mixed inoculation have not been found, significant difference in ratios of fresh mass of the entire plant to nodule number was evident when these two types of inoculations were compared (Table II). A possible explanation for this result might be that the concentration of several Nod factors produced by particular strains in the mixed inoculation is substantially greater than in a single strain inoculation. Nod factors stimulate nodule organogenesis (Perret et al., 2000; Spaink, 2000) and that nodule number increase was not accompanied by increased plant growth probably due to the relatively short timeframe of the experiment. This observation is consistent with our previous studies, in which treatment of clover seeds with Nod factors under controlled conditions enhanced the growth of clover only when a Nod factor was applied in appropriate concentration (Maj et al., 2009).

In summary, our data revealed that $R$. leguminosarum strains investigated in the experimental competition model were greatly differentiated with respect to competitiveness for nodule occupancy. In the mixed inoculation of clover plants, nodule coinfection by two or three strains was commonly observed. The prevalence of nodule coinfection by native soil population is yet to be determined.

\section{Acknowledgements}

The research reported in this paper was funded in part by a grants of Ministry of Sciences and Higher Education of Poland nr N N304 026734 and N N301 028734.

\section{Literature}

Bromfield E.S.P. 1984. Variation in preference for Rhizobium meliloti within and between Medicago sativa cultivars grown in soil. Appl. Environ. Microbiol. 48: 1231-1236.

Cresswell A., L. Skot and A.R. Cookson. 1994. The construction, detection and use of bioluminescent Rhizobium leguminosarum biovar trifolii strains. J. Appl. Bacteriol. 77: 656-665.

Depret G. and G. Laguerre. 2008. Plant phenology and genetic variability in root and nodule development strongly influence genetic structuring of Rhizobium leguminosarum biovar viciae populations nodulating pea. New Phytol. 179: 224-235.

Dowling D.N. and W.J. Broughton. 1986. Competition for nodulation of legumes. Annu. Rev. Microbiol. 40: 131-157.

Duodu S., C. Brophy, J. Connolly and M.M. Svenning. 2009. Competitiveness of native Rhizobium leguminosarum bv. trifolii strain for nodule occupancy is manifested during infection. Plant Soil 318: 117-126.

Duodu S., T.V. Bhuvaneswari, J. Gudmundsson and M.M. Svenning. 2005. Symbiotic and saprophytic survival of three unmarked Rhizobium leguminosarum biovar trifolii strains introduced into the field. Environ. Microbiol. 7: 1049-1058.
Gage D.J. 2004. Infection and invasion of roots by symbiotic nitrogen-fixing rhizobia during nodulation of temperate legumes. Microbiol. Mol. Biol. Rev. 68: 280-300.

Jones K.M., H. Kobayashi, B.W. Davies, M.E. Taga and G.C. Walker. 2007. How symbionts invade plants: the Sinorhizobium-Medicago model. Nature 5: 619-633.

Kiers E.T., R.A. Rousseau and R.F.Denison. 2006. Measured sanctions: legume hosts detect quantitative variation in rhizobium cooperation and punish accordingly. Evol. Ecol. Res. 8: 1077-1086. Lakzian A., P. Murphy, A. Turner, J.L. Beynon and K.E. Giller. 2002. Rhizobium leguminosarum bv. viciae populations in soils with increasing heavy metal contamination: abundance, plasmid profiles, diversity and metal tolerance. Soil Biol. Biochem. 34: 519-529.

Lopez-Garcia S.L., T.E.E. Vazquez, G. Favelukes and A.L. Lodeiro. 2002. Rhizobial position as a main determinant in the problem of competition for nodulation in soybean. Environ. Microbiol. 4: 216-224.

Mabood F., W.J. Jung and D.L. Smith. 2008. Signal in the underground: microbial signaling and plant productivity. In: Nautiyal C.S., P.E. Dion and V.L. Chopra (eds.). Molecular mechanisms of plant and microbe coexistence. Springer-Verlag, Berlin, Heidelberg.

Maier R.J. and E.W. Triplett. 1996. Toward more productive, efficient, and competitive nitrogen-fixing symbiotic bacteria. Crit. Rev. Plant Sci. 15: 191-234.

Maj D., J. Wielbo, M. Marek-Kozaczuk and A. Skorupska. 2009. Pretreatment of clover seeds with Nod factors improves growth and nodulation of Trifolium pratense. J. Chem. Ecol. 35: 479-487.

Maj D., J. Wielbo, M. Marek-Kozaczuk and A. Skorupska. 2010. Response to flavonoids as a factor influencing competitiveness and symbiotic activity of Rhizobium leguminosarum. Microbiol. Res. 165: 50-60.

Masson-Boivin C., E. Giraud, X. Perret and J. Batut. 2009. Establishing nitrogen-fixing symbiosis with legumes: how many rhizobium recipes? Trends Microbiol. 17: 458-466.

Mellor H.Y., A.R. Glenn and M.J. Dilworth. 1987. Symbiotic and competitive properties of motility mutants of Rhizobium trifolii TA1. Arch. Microbiol. 148: 34-39.

Peoples M.B, J.K. Ladha and D.F. Herridge. 1995. Enhancing legume $\mathrm{N}_{2}$ fixation through plant and soil management. Plant Soil 174: 83-101.

Perret, X., C. Staehelin and W.J. Broughton. 2000. Molecular basis of symbiotic promiscuity. Microbiol. Mol. Biol. Rev. 64 180-201.

Ramos M.G., M.A. Villatoro, S. Urquiaga, B.J. Alves and R.M. Boddey. 2001. Quantification of the contribution of biological nitrogen fixation. J. Biotechnol. 91: 105-115.

Rangin, C., B. Brunel, J.-C. Cleyet-Marel and G. Bena. 2008. Effects of Medicago truncatula Genetic Diversity, Rhizobial Competition, and Strain Effectiveness on the Diversity of a Natural Sinorhizobium Species Community. Appl. Environ. Microbiol. 74: 5653-5661.

Sachs J.L., S.W. Kembel, A.H. Lau and E.L. Simms. 2009. In situ phylogenic and diversity of wild Bradyrhizobium communities. Appl. Environ. Microbiol. 75: 4727-4735.

Sambrook, J., E.F. Fritsch and T. Maniatis. 1989. Molecular Cloning: a Laboratory Manual. $2^{\text {nd }}$ ed. Cold Spring Harbor, NY: Cold Spring Harbor Laboratory.

Sessitsch A., G. Hardarson, W.M. de Vos and K.J. Wilson. 1998. Use of marker genes for competition studies of Rhizobium. Plant Soil 204: 35-45.

Sharma P.K., R.C. Anand and K. Lakshminarayana. 1991. Construction of Tn5 tagged mutants of Rhizobium spp. (Cicer) for ecological studies. Soil Biol. Biochem. 23: 881-885. 
Silva C., F.L. Kan and E. Martínez-Romero. 2007. Population genetic structure of Sinorhizobium meliloti and S. medicae isolated from nodules of Medicago spp. in Mexico. FEMS Microbiol. Ecol. 60: 477-489.

Spaink H.P. 2000. Root nodulation and infection factors produced by rhizobial bacteria. Annu. Rev. Microbiol. 54: 25-288.

Streeter J.G. 1994. Failure of inoculant rhizobia to overcome the dominance of indigenous strains for nodule formation. Can. J. Microbiol. 40: 513-522.

Stuurman N., C. Pacios Bras, H.R.M. Schlaman, A.H.M. Wijfjes, G. Bloemberg and H.P. Spaink. 2000. Use of green fluorescent protein color variants expressed on stable broad-hostrange vectors to visualize rhizobia interacting with plants. Mol. Plant-Microbe Interact. 13: 1163-11699.

Svenning M.M., J. Gudmundsson, I.L. Fagerli and P. Leinonen. 2001. Competition for nodule occupancy between introduced strains of Rhizobium leguminosarum bv. trifolii and its influence on plant production. Ann. Bot. 88: 781-787.

Timmers A.C., E. Soupène, M.C. Auriac, F. de Billy, J. Vasse, P. Boistard and G. Truchet. 2000. Saprophytic intracellular rhizobia in alfalfa nodules. Mol. Plant-Microbe Interact. 13: 1204-1213.
Vasse J., F. de Billy, S. Camut and G. Truchet. 1990. Correlation between ultrastructural differentiation of bacteroids and nitrogen fixation in alfalfa nodules. J. Bacteriol. 172: 4295-4306.

Vincent J.M. 1970. A manual for the practical study of root nodule bacteria. International biological program handbook no.15. Blackwell Scientific Publications Ltd, Oxford, UK.

Wielbo J. and A. Skorupska. 2001. Construction of improved vectors and cassettes containing gus $A$ and antibiotic resistance genes for studies of transcriptional activity and bacterial localization. J. Microbiol. Methods 45: 197-205.

Wielbo J., M. Marek-Kozaczuk, A. Kubik-Komar and A. Skorupska. 2007. Increased metabolic potential of Rhizobium spp. is associated with bacterial competitiveness. Can. J. Microbiol. 53: 957-967.

Wielbo J., Marek-Kozaczuk M., Mazur A., Kubik-Komar A. and A. Skorupska. 2010. Genetic and metabolic divergence within a Rhizobium leguminosarum bv. trifolii population recovered from clover nodules. Appl. Environ. Microbiol. 76: 45934600 .

Wilson R.A., B.A. Handley and J.E. Beringer. 1998. Bacteriocin production and resistance in a field population of Rhizobium leguminosarum bv. viciae. Soil Biol. Biochem. 30: 413-417. 